\title{
Study on Quantification Method for the Risk of Soil-Plant-Human System Environmental Pollution Caused by Sewage Irrigation in Agriculture
}

\section{Xin Huang† and Lin Qiu}

School of Water Resources, North China University of Water Resources and Electric Power, Zhengzhou, Henan, 450046, China

†Corresponding author: Xin Huang; huangxin0013@163.com

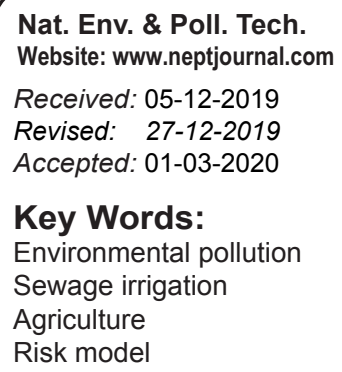

\begin{abstract}
Long-term sewage irrigation can cause accumulation of contaminants in soil, which imposes severe damages to soil and plants and further triggers many chronic diseases in human bodies via the food chain. In this paper, the effect of sewage irrigation on changes in concentration of contaminants in soil and its relationship with the concentration of contaminants in the main agricultural plants are discussed, and a health risk assessment is performed on the contaminant exposure suffered by people in the sewage irrigation area. Based on this, an environmental pollution risk model for the soil-plant-human system was established for research on the acceptable irrigation concentration of contaminants in sewage and the safe service period of sewage irrigation. A practical example adopted in this paper proves that arsenic pollution caused by sewage irrigation to soil-plant-human body system in the irrigation area imposes a comprehensive risk degree of 0.40 , the acceptable arsenic irrigation concentration is $0.086 \mathrm{mg} / \mathrm{L}$ and the safe service period for this irrigation area is 150 years. Thus, the reclaimed water shall be subject to innocuous disposal under scientific guidance for agricultural irrigation.
\end{abstract}

\section{INTRODUCTION}

With the rapid development of Chinese economy and increasingly improved living standards, water used for irrigation is growingly reduced due to the excessive industrial and domestic water demand, which causes a growing shortage of water used for agriculture (Bibliometric 2016). It has been a general practice in China that sewage was used for irrigation, which can provide fertilizer resources. Nevertheless, due to poor sewage processing capacity, high sewage processing cost and low awareness of environmental protection, a large volume of sewage that fails to pre-processing is used for irrigating farmland, significantly damaging water quality and causing environmental pollution (Zeng et al. 2015, Jiang et al. 2017). In recent years, scholars have made great efforts into studies of environmental pollution caused by sewage irrigation (Liu et al. 2015, Liu et al. 2016, Wu et al. 2018).

In this paper, the author will make a discussion over the effect of concentration of contaminants in sewage used for irrigation, on changes in concentration of contaminants in soil, the correlation between the concentration of contaminants in soil and those in the main agricultural plant. According to a survey performed on habits of people in sewage irrigation area, a quantification analysis on the process that how people are exposed to contaminants in the environment and a supporting health risk assessment has been performed, based on which, an environmental risk pollution model for the soil-plant-human system was established, whereby a study on the acceptable irrigation concentration of contaminants in sewage and the safe service period of sewage irrigation is made.

\section{MATERIALS AND METHODS}

\section{Heavy Metal Accumulation in Soil Due to Sewage Irrigation in Farmland}

The annual accumulation of heavy metals (annual residue) in soil is calculated with the formula (1):

$$
W=K(B+R)
$$

Where, $W$ is the annual accumulation of the heavy metal in soil, $\mathrm{mg} / \mathrm{kg} ; B$ is the soil background value, $\mathrm{mg} / \mathrm{kg} ; R$ is the annual input of the contaminant into soil, $\mathrm{mg} / \mathrm{kg}$; $K$ is the annual residual rate of the contaminant in soil, $\%$.

Given the fact that historically annual production of pollution sources has been stable, the changes in heavy metal concentrations in local soil can be regarded as increasing in arithmetic progression. In the case that annual input of the contaminant into the soil is inaccessible and experimental data from local pot planting and community simulations are 
not available, formula (2) can be used to predict the accumulation of the contaminant within a certain year and the safe service period during which sewage irrigation is tolerant in soil (Huang \& Qiu 2017).

$$
W=N_{w} \cdot x+W_{0}, \quad n=\left(S_{i}-W_{0}\right) / x, \quad x=\left(W_{0}-B\right) / N_{0}
$$

Where, $W$ is the predicted accumulation of the contaminant in soil within certain years, $\mathrm{mg} / \mathrm{kg} ; N_{w}$ is the predicted sewage irrigation period; $x$ is the annual increment of the contaminant in soil, $\mathrm{mg} / \mathrm{kg} ; W_{0}$ is the accumulation of the contaminant in the soil in the current year, $\mathrm{mg} / \mathrm{kg} ; n$ is the safe period; $S_{i}$ is the environmental standards for soil, $\mathrm{mg} /$ $\mathrm{kg} ; B$ is the soil background value, $\mathrm{mg} / \mathrm{kg} ; N_{0}$ is the period amid which sewage irrigation has been applied.

\section{Heavy Metal Concentration in Agricultural Plants Irrigated by Sewage}

Reports from many scholars indicate that in a certain area, heavy metal concentration in the agricultural plants is correlated with heavy metal concentrations in soil (Li 2002, Liu \& Jiang 2004, Li et al. 2006). In this study, correlation analysis has been performed on concentrations of heavy metals in soil from each sampling site and the concentrations of heavy metals in the main agricultural plants.

\section{Health Risk Assessment on Heavy Metal Exposure in Sewage Irrigation Area}

The lifetime risk of chronic heavy metal poisoning imposed on people in sewage irrigation area $(G)$ is characterized by three indicators, i.e., reference dose of heavy metal accumulation $\left(G_{f} M\right)$, lifetime accumulation of heavy metal in people in sewage irrigation area $\left(U_{\text {lifetime }}\right)$ and prevalence rate of heavy metal poisoning $(P)$, as below:

$$
G=\frac{U_{\text {lifetime }}}{G_{f} M} \times P
$$

Assuming that 80 years is the life expectancy of people in sewage irrigation area, i.e., safe period, and $U_{\text {lifetime }}$ is calculated by the following formula:

$$
\begin{gathered}
U_{\text {lifetime }}=U_{\text {diet (lifetime) }} \\
U_{\text {diet (lifetime) }}=\sum_{=1}^{80} \sum S_{(i, j)} \cdot h_{(i, j)}
\end{gathered}
$$

Where, $U_{\text {diet (lifetime) }}$ is the lifetime exposure of heavy meal in diet for people in sewage irrigation area; $S_{(i, j)}$ is the total intake of food $j$ in the year $i, \mathrm{~kg} / \mathrm{a} ; h_{(i, j)}$ is the heavy metal concentration in food $j$ in the year $i, \mathrm{mg} / \mathrm{kg}$.

By performing epidemics surveys on arsenic poisoning of people in sewage irrigation area, and analysing people's cumulative exposure to arsenic, some scholars (Shang et al. 2002) have summarized the relationship between prevalence rate of arsenic poisoning in people $(P, \%)$ and the cumulative exposure of arsenic $(U, \mathrm{mg})$.

\section{Quantification Model for Risk Caused by Sewage Irrigation on the Soil-Plant-Human and Analysis of Safe Period and Acceptable Irrigation Concentrations of Heavy Metals in Soil}

After analysing the health risk caused by exposure to heavy metals, authors have further established a quantification model to study the environmental risk of heavy metal pollution on the soil-plant-human system in sewage irrigation area, as described in formula (4):

$$
M_{s}=G /[M]
$$

Where, $M_{s}$ is the risk degree of pollution on the soilplant-human system caused by sewage irrigation; $[M]$ the permissible risk degree. $M_{s} 1$ means that the concentration of heavy metal in the sewage used for irrigation exceeds the environmental tolerance limit for such heavy metal and irrigation of farmland with this sewage will cause pollution of the soil-plant-human system; $M_{s}<1$ means that the risk of soil-plant-human system pollution caused by a heavy metal contained in sewage used for irrigation is acceptable.

Given the said study on the risk caused by sewage irrigation to soil-plant-human system pollution and with reference to data from U.S. Environmental Protection Agency, the health risk analysis result obtained by formula (4) when the risk degree of chronic heavy metal poisoning to people in sewage irrigation area $(G)$ is lower than the permissible risk of such heavy metal $[M]$ is acceptable (i.e., $G<[M]$ ). The safe period of sewage irrigation defined in this study means the period during which the cumulative heavy metal exposure risk imposed on existing residents in the sewage irrigation area is always lower than the permissible risk when sewage containing a certain concentration of a heavy metal containment is used for farmland irrigation on a long-term basis. Accordingly, the acceptable risk irrigation concentration of a heavy metal contaminant in the soil-plant-human system is defined as the maximum permissible concentration of heavy metal in the sewage used for irrigation when the cumulative heavy metal exposure risk imposed on existing residents in the sewage irrigation area is lower than the permissible risk of such heavy metal exposure. Thus, the acceptable risk irrigation concentration is not fixed but changed with the safe period required for a sewage irrigation area.

\section{THE CASE STUDY OF ENVIRONMENTAL POLLUTION CAUSED BY SEWAGE IRRIGATION IN AGRICULTURE IN YELLOW RIVER BASIN}

\section{General Information}

For the sewage irrigation area in the Yellow River Basin, there are detailed monitoring data. By 2018 sewage had been applied to irrigation in this area for 20 consecutive 
years. Specific data are described as below. Topsoil depth is $15 \sim 45 \mathrm{~cm}$. Soil background values: cadmium $(\mathrm{Cd})$ is 0.16 $\mathrm{mg} / \mathrm{kg}, \mathrm{Hg}$ is $0.09 \mathrm{mg} / \mathrm{kg}$, arsenic (As) is $8.9 \mathrm{mg} / \mathrm{kg}$ and lead $(\mathrm{Pb})$ is $16.25 \mathrm{mg} / \mathrm{kg}$. The annual volume of irrigation water is $4500 \mathrm{~m}^{3} / \mathrm{hm}^{2}$. The main agricultural plant in this area is rice whose whole growth period is from April to September.

Scholars concluded that the residual accumulation rate of heavy metal in sewage irrigated soil is often higher than $90 \%$ through community or pot planting experiments (Huang $\&$ Wang 2009). Given the fact that heavy metals in sewage pose the most significant harm to environment and people in the irrigation area, arsenic (As) is taken as an example, in this study, to calculate the pollution risk imposed on the soil-plant-human system.

\section{Change in Concentration of Arsenic in Soil}

It is assumed that the concentration of arsenic in soil is an arithmetic progression, from which, the cumulative concentration of arsenic in soil in 2018 can be obtained. The average annual increment of arsenic concentration in the soil can be calculated, $x=\left(W_{0}-B\right) / N_{0}=0.295 \mathrm{mg} / \mathrm{kg}$. It can be seen from formula (2) how the concentration of arsenic changes in soil irrigated by sewage in a certain year, $W=N_{w} \cdot x+W_{0}=$ $0.295 N_{w}+8.9\left(N_{w}=1,2,3, \ldots w\right)$.

\section{Determination of Concentration of Arsenic in the Soil- Plant System}

Rice is the primary food taken by people in the irrigation area. According to the detected concentration of arsenic in rice harvested from sewage irrigation area and the concentration of arsenic in soil, the correlation equation between concentration of arsenic in rice, $a(\mathrm{mg} / \mathrm{kg})$ and the concentration of arsenic in soil, $b(\mathrm{mg} / \mathrm{kg})$ can be obtained by fitting, $a=$ $7.9 \times 10^{-3} b-4.89 \times 10^{-2}\left(r^{2}=0.98\right)$.

\section{Calculation of Cumulative Arsenic Exposure in Human Body}

Rice consumed by each adult (over 18 years old) per day in the sewage irrigation area is $505 \mathrm{~g}$, the annual rice intake for each adult is $S=505 \mathrm{~g} / \mathrm{d} \times 365 \mathrm{~d}=184325 \mathrm{~g}$. According to Recommended Nutrition Supplies in Daily Diet (revised), the average food consumed by a minor is about 0.669 time of that by an adult.

The concentration of arsenic in rice is taken as the average concentration over such 20 years. The $h(0.131 \mathrm{mg} / \mathrm{kg})$ can be calculated from the correlation between the concentration of arsenic in rice, $a(\mathrm{mg} / \mathrm{kg})$, and the concentration of arsenic in soil, $b(\mathrm{mg} / \mathrm{kg})$. Further, with c into relevant formulas, the arsenic exposures $U_{\text {adult }}$ and $U_{\text {minor }}$ in the diet of residents in sewage irrigation area in 2018 can be obtained, $U_{\text {adult }}=$ $S h=24.147 \mathrm{mg}, U_{\text {minor }}=0.669 U_{\text {adult }}=16.154 \mathrm{mg}$.

Residents of different ages are influenced by arsenic for different periods and the lifetime arsenic exposure for one person is different from that for another. Two cases are discussed in this study depending on how long each resident has been living in the sewage irrigation area. The first case applies to residents who were born in 2018 and have been living there since then, they are subject to the highest arsenic exposure risk, with the lifetime arsenic exposure caused by rice consumption from the soil-plant system.

$U_{\text {lifetime }}=0.669 \cdot \sum_{i=2019}^{2036} U_{\text {diet }(i)}+\sum_{j=2037}^{2098} U_{\text {diet }(j)}=1.788 \mathrm{~g}$

The second case applies to residents who had lived in the soil-plant system for more than 20 years, with the highest arsenic exposure risk $U_{\text {current }}=20 \cdot U_{\text {adult }}=0.483 \mathrm{~g}$

\section{Health Risk Caused by Arsenic Pollution}

$G_{f} M$ is taken as $200 \mathrm{~g} / \mathrm{d}$ because no chronic poisoning reaction occurs when the human body intakes arsenic with a dose of $200 \sim 250 \mathrm{~g} / \mathrm{d}$ (Qiu \& Wang 2003). According to the relationship between prevalence rate arsenic poisoning among people $(P, \%)$ and cumulative arsenic exposure $(U), 2018$ prevalence rate of arsenic poisoning among people in the irrigation area is $1 \%$. According to Provisional Regulations on Classification of Regional Arsenic Poisoning Areas and Clinical Diagnosis, this area is classified as a mild regional arsenic poisoning area.

The arsenic exposure health risk $G_{\text {lifetime }}$ for residents born in 2018 is $G_{\text {lifetime }}=U_{\text {lifetime }} / G_{f} M \times P=0.003$, and the arsenic exposure health risk $G_{\text {current }}$ for people who had been living in the irrigation area since sewage was used for irrigation is $G_{\text {current }}=U_{\text {current }} / G_{f} M \times P=0.0008$.

For residents who had been living in the irrigation area for more than 20 years, the comprehensive risk of land-planthuman system pollution caused by sewage irrigation $M_{s}=$ $G_{\text {current }} /[M]=0.40$.

For residents who were born in 2018, the lifetime risk of land-plant-human system pollution caused by sewage irrigation $M_{s}=G_{\text {lifetime }} /[M]=1.50>1$, which means that if the current sewage irrigation is continued without any improvement action, residents who were born in 2018 and would live in the irrigation area for their lifetime would be harmed.

\section{Analysis of Acceptable Risk Irrigation Concentration of Arsenic in Land-Plant-Human System and Safe Period}

Given the available data about the irrigation area, from an analysis of annual sewage volume used for irrigation and average annual increment of arsenic concentration on soil, 


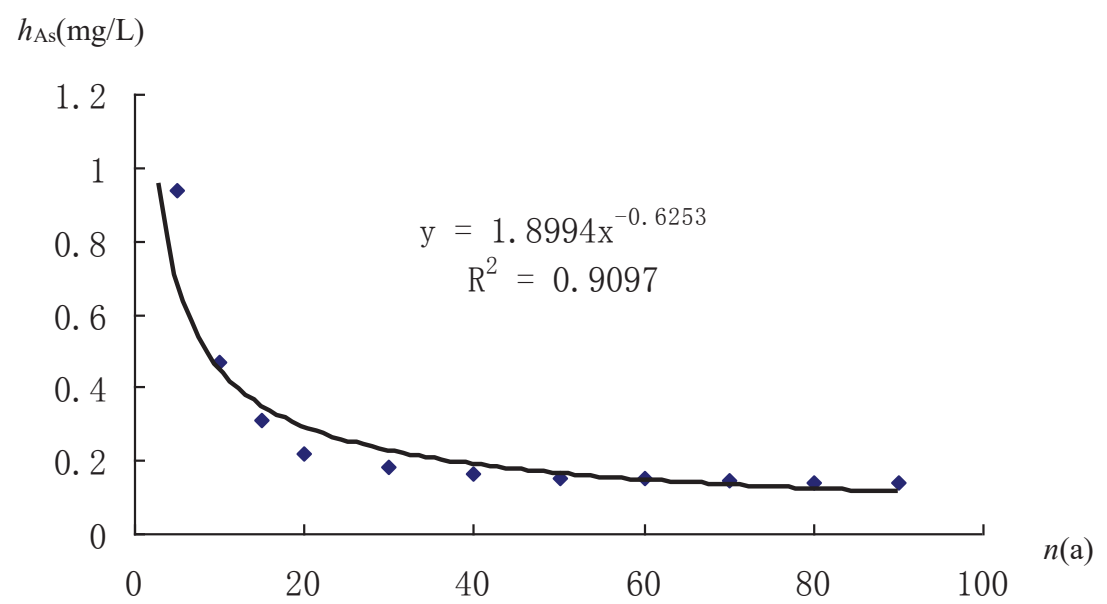

Fig. 1: The fit curve relationship between $n$, safe period of sewage irrigation, and $h_{\mathrm{As}}$, acceptable risk irrigation concentration of arsenic in the soil-plant-human system.

it can be known that the average concentration of arsenic in sewage used for irrigating main agricultural plant in this area is $0.164 \mathrm{mg} / \mathrm{L}$. This concentration would impose cumulative health risks at different degrees to people born in 2018 in this irrigation area. To have residents born in 2018 subject to a health risk caused by arsenic exposure of lower than $[M]$, the acceptable risk irrigation concentration of arsenic in sewage is $0.086 \mathrm{mg} / \mathrm{L}$, as calculated from the model adopted for risk assessment of soil-plant-human system pollution. That is to say, when the concentration of arsenic in sewage used for irrigation is not higher than $0.086 \mathrm{mg} / \mathrm{L}$, all residents living in the irrigation area experience a health risk caused by arsenic exposure that is lower than $[M]$ and the safe period of sewage irrigation is at least 150 years.

For the development of irrigation systems for an irrigation area, the effect of changes in contaminants contained in sewage and changes in management standards on safe service period of sewage irrigation should be clearly understood. A fit curve relationship between $n$, the safe period of sewage irrigation, and $h_{\mathrm{As}}$, acceptable risk irrigation concentration of arsenic in the soil-plant-human system is plotted in Fig. 1.

With reference to the analysis of acceptable risk irrigation concentration of arsenic for residents born in 2018, the acceptable risk irrigation concentration of arsenic in sewage when the safe period is 150 years can be calculated from Fig. 1. As $n$, the safe period of sewage irrigation becomes longer, the acceptable risk irrigation concentration of arsenic, $h_{\mathrm{As}}$, is stabilized around $0.086 \mathrm{mg} / \mathrm{L}$. The current average concentration of arsenic in sewage used for irrigation is $0.164 \mathrm{mg} / \mathrm{L}$, which in turn, with the help of the curve described in Fig. 1 , can help calculate the safe period $n=90.5$ years. Without improvement actions, the safe period of sewage irrigation in this irrigation area cannot be increased.

\section{CONCLUSIONS}

The practical example provided in this study indicates that the comprehensive risk of the soil-plant-human system pollution caused by 20 -year sewage irrigation is 0.40 , the acceptable risk irrigation concentration of arsenic in sewage is $0.086 \mathrm{mg} / \mathrm{L}$ and the corresponding safe period is at least 150 years. The sewage irrigation has caused significant pollution on the soil-plant-human system and a procedure-based management system for sewage irrigation should be established and improved as soon as possible by specifying the sewage irrigation ways, times, optimum irrigation time and irrigation quota for the main agricultural plan that apply to different sewage types and different soil conditions, to achieve reasonable and proper sewage irrigation.

Despite soil's self-cleaning ability which helps degrade organic pollution in soil within a certain period, long-term irrigation with a large amount of sewage definitely can cause accumulation of contaminants, which imposes great harm to the soil-plant-human system. The sewage irrigation pollutes soil and further agricultural plant; contaminants contained in agricultural plant enter and accumulate in the human body via the food chain to trigger many chronic diseases. The theory and model presented in this paper can describe the pollution degree of the soil-plant-human system by sewage irrigation from a quantitative perspective. The influence of sewage irrigation on the soil-plant-human system is enduring and cumulative, and the mechanism of contaminant migration, transformation and accumulation is quite complicated. The study result presented in this paper can provide some reference for practices, but more deep studies should be pursued in the future. Next, more reasonable methods will be developed to describe the risk caused by sewage irrigation, and the indicators that characterize the risk of soil-plant-human system 
pollution improved, and the standards for the classification of risks of soil-plant-human system pollution developed.

\section{REFERENCES}

Bibliometric, S.M. 2016. Analysis of research on wastewater irrigation during 1991-2014. Irrigation and Drainage, 65(5): 644-653.

Huang, C.G. and Wang, X. 2009. China's farmland sewage irrigation development and its impact on crop research. Journal of Anhui Agricultural Sciences, 37(22): 10692-10693.

Huang, X. and Qiu, L. 2017. Theoretical exploration of risk analysis of sewage irrigation in farmland. Nature Environment and Pollution Technology, 16(1): 67-73.

Jing, X., Yao, G.J., Liu, D.H., Liang, Y.R., Luo, M., Zhou, Z.Q. and Wang, P. 2017. Effects of wastewater irrigation and sewage sludge application on soil residues of chiral fungicide benalaxyl. Environmental Pollution, 224: 1-6.

Li, H.Y. 2002. The relationship between the heavy metals Cd, $\mathrm{Zn}$ in Crop and soil properties, the total content of $\mathrm{Cd}$ and $\mathrm{Zn}$. Ningxia Engineering Technology, 1(3): 221-223.

Liu, Y.L. and Jiang, X.Y. 2004. Evaluation of heavy metal pollution of soil and crops in Baima village Zhuzhou City. Soils, 36(5):551-556.
Li, Q.X., Huang, Y.Y., Zhao, Y.H. and Huang, Y.Z. 2006. Study on absorption of pollutants of irrigating water by several vegetables and their soil. Ecologic Science, 25(3): 216-221.

Liu, Y., Wang, H.F., Li, X.T. and Li, J.C. 2015. Heavy metal contamination of agricultural soils in Taiyuan, China. Pedosphere, 25(6): 901-909.

Liu, B.L., Ma, X.W., Ai, S.W., Zhu, S.Y., Zhang, W.Y. and Zhang, Y.M. 2016. Spatial distribution and source identification of heavy metals in soils under different land uses in a sewage irrigation region, northwest China._Journal of Soils and Sediments, 16(5): 1547-1556.

Qiu, F.G. and Wang, X.C. 2003. Assessing methods for health risks of reclaimed water. Environmental Pollution and Control, 25(1): 49-51.

Shang, Q., Ren, X.Q. and Li, J.R. 2002. Estimation of arsenic accumulative intake and residents' health effects in an air pollution area-relationship between arsenic accumulative intake level and arsenicism prevalence. Journal of Hygiene Research, 31(5): 926-929.

Wu, B., Guo, S.H., Li, X.J. and Wang, J.N. 2018. Temporal and spatial variations of polycyclic aromatic hydrocarbons (PAHs) in soils from a typical organic sewage irrigation area. Science of the Total Environment, 613: 513-520.

Zeng, X.F., Wang, Z.W., Wang, J., Guo, J.T., Chen, X.J. and Zhuang, J. 2015. Health risk assessment of heavy metals via dietary intake of wheat grown in Tianjin sewage irrigation area._Ecotoxicology, 24(10): 2115-2124. 